\title{
Agricultura de precisión con drones para control de enfermedades en la planta de arroz
}

\section{Precision agriculture with drones to control diseases in the rice plant}

\author{
Jorge A. Barraza ${ }^{l^{*}}$, Eduardo J. Espinoza ${ }^{l}$, Alonso G. Espinos $1^{1}$, Jose Serracin ${ }^{l}$ \\ ${ }^{1}$ Licenciatura en Ingeniería Electromecánica, Centro Regional de Chiriqui, Universidad Tecnologica de Panamá,
}

Resumen Este texto trata sobre la detección de enfermedades en la planta de arroz, implementando agricultura de precisión con drones. Los cuales emplean un sensor de color (cámara) que será capaz de identificar el espectro de colores en los cultivos, es decir, reconocer el área específicamente afectada dentro del mismo, acto seguido, el agricultor podrá aplicar los químicos necesarios limitándose a esta zona, dicho de otra manera, se elimina el método actual de trata de enfermedades en el cual se aplican los pesticidas al cultivo entero, en efecto se reducirán: costos en compra de productos químicos, contaminación de suelos al no utilizar una dosis adecuada. Además, mejora el problema de eutrofización, a saber, que, actualmente presentamos uno en el área de pedregal y mejora la calidad de los productos para nuestra alimentación.

Palabras clave Agricultura de precisión, control del arroz, drones, espectrofotometría.

\begin{abstract}
This text deals with the detection of diseases in the rice plant, implementing precision agriculture with drones. They use a color sensor (camera) that will be able to identify the spectrum of colors in the crops, which means, recognize the area that is specifically affected within it, then the farmer can apply the necessary chemicals limited to this area, In this way, the current method of treating diseases in which pesticides are applied to the whole crop is eliminated, in effect they will reduced: costs in buying chemical products, soil contamination by not using an adequate dose. Also, improving the problem of eutrophication, currently that it is presented in Pedregal and improve the quality of the products for our food.
\end{abstract}

Keywords Precision farming, rice control, drones, spectrophotometry.

* Corresponding author:jorge.barraza.94@ hotmail.com

\section{Introducción}

El arroz es parte de la cultura alimenticia del panameño, en este sentido, se iniciaron los trabajos de investigación en las plantas de arroz con énfasis en la detección de enfermedades o plagas a las cuales se ve sometida la planta de arroz en nuestros suelos.

Como propósito tenemos, presentar una base de datos sobre el espectro de colores dentro de las plantaciones del arroz, a saber, que, cuando esta planta se ve afectada su color natural cambia y atraviese por distintas degradaciones de colores dependiendo de la afectación, por ejemplo, si se enfrenta al acaro Spinki la misma se torna amarillenta.

En la agricultura la espectrofotometría representa una gran ventana de posibilidades, tomando como ejemplo estudios ya realizados en este caso para cultivos de papas [1], sin embargo, validan nuestra incursión de su uso, más extrapolándonos a cultivos en el arroz.
El arroz se puede ver afectado por distintos agentes, sin embargo, a través del tiempo se desarrollan formas de contrarrestar los mismos mediante control biológico [2].

Como el método tradicional empleado por agricultores nacionales consiste en combatir las enfermedades de los cultivos mediante una aplicación masiva del pesticida o producto químico que requiera la afectación, sin reparar en los efectos secundarios que esto conlleva, puesto que como productores no pierden tiempo en averiguar detalladamente que parte se ve afectada específicamente, en consecuencia los suelos reciben una cantidad considerable de químicos, de modo que, estos con el paso del tiempo y las lluvias viajan por el subsuelo y pueden llegar a vías acuíferas en poblaciones cercanas a la plantación, así que las personas que habitan en estas zonas rurales presentan enfermedades proporcionadas por la contaminación de las aguas que utilizan para consumo y uso cotidiano. 
Otro problema paralelo es cuando estas aguas contaminadas llegan a mar abierto, en particular, podemos resaltar la situación en el área de Pedregal, provincia de Chiriquí, en donde los pescadores comunican su inquietud, así pues, cada vez tienen que navegar más lejos para lograr satisfacer su producción, esto se debe a un problema de eutrofización el cual consiste en la contaminación de las aguas por lo cual la vida marina cercana a la costa se ve reducida y recurren a moverse a zonas distantes.

\subsection{Manejo integrado del cultivo de arroz en Panamá}

Por lo que se refiere a identificación, biología y muestreo de insectos-plagas y benéficos: contribución para el manejo integrado de plagas en el cultivo del arroz, se utilizó como fuente de datos, investigaciones que presenta el IDIAP (Instituto de Investigación Agropecuaria de Panamá) con el cual recolectamos la data necesaria para tener un mejor panorama de las plagas y enfermedades que enfrentamos en nuestro país, así mismo, como afectan los cultivos y como se ven las representaciones de estas afectaciones en el cambio de color del mismo.

Las plagas, como lo son malezas e insectos del arroz se les concede la pérdida de un $35 \%$ en cuanto a producción. En la situación del arroz irrigado, el manejo de los insectos y plagas representa un $6 \%$ de costos en producción.

En Panamá se obtuvieron resultados similares gracias a Zachrisson en el año 1998, donde el costo de la producción en cuanto al control de insectos en el arroz, bajo las condiciones de riego, se dio en un 7\%, por consiguiente, los insectos se consideraron una limitante de gran importante en el desarrollo con la producción de arroz [3].

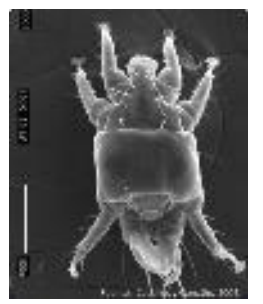

Figura 1. Vista del macho Spinki desde un microscopio electrónico.

Se obtiene información que asegura que el arroz rojo es la más importante maleza del cultivo. Se verificó la tolerancia de los cultivares promisorios en cuanto al arroz del IDIAP VF 72_10 y VF 147_09, a la plaga del Steneotarsonemus spinki (figura 1).

La información dada de micronutrientes como por ejemplo el zinc y el silicio, en la especie del IDIAP FL 13711, incrementa el desarrollo. Las curvas de absorción nos muestran que, en condiciones de riego, se obtiene gran cantidad de nutrientes [4].

\subsection{Sistema de manejo de data en fertilización de precisión.}

Un objetivo posterior a la detección de plagas en la planta de arroz es que a su vez el dron pueda determinar la zona afectada, y sea capaz de actuar mediante el riego de fertilizantes al área, la data recolectada en esta fertilización de precisión pasaría por un proceso para posteriormente ser analizada por el software para esto se desarrolla un diagrama de flujo (figura 2) que cuente con estaciones de referencia continuamente operadas o como sus siglas en ingles nos indican (CORS, Continuously Operating Reference Stations) [5].

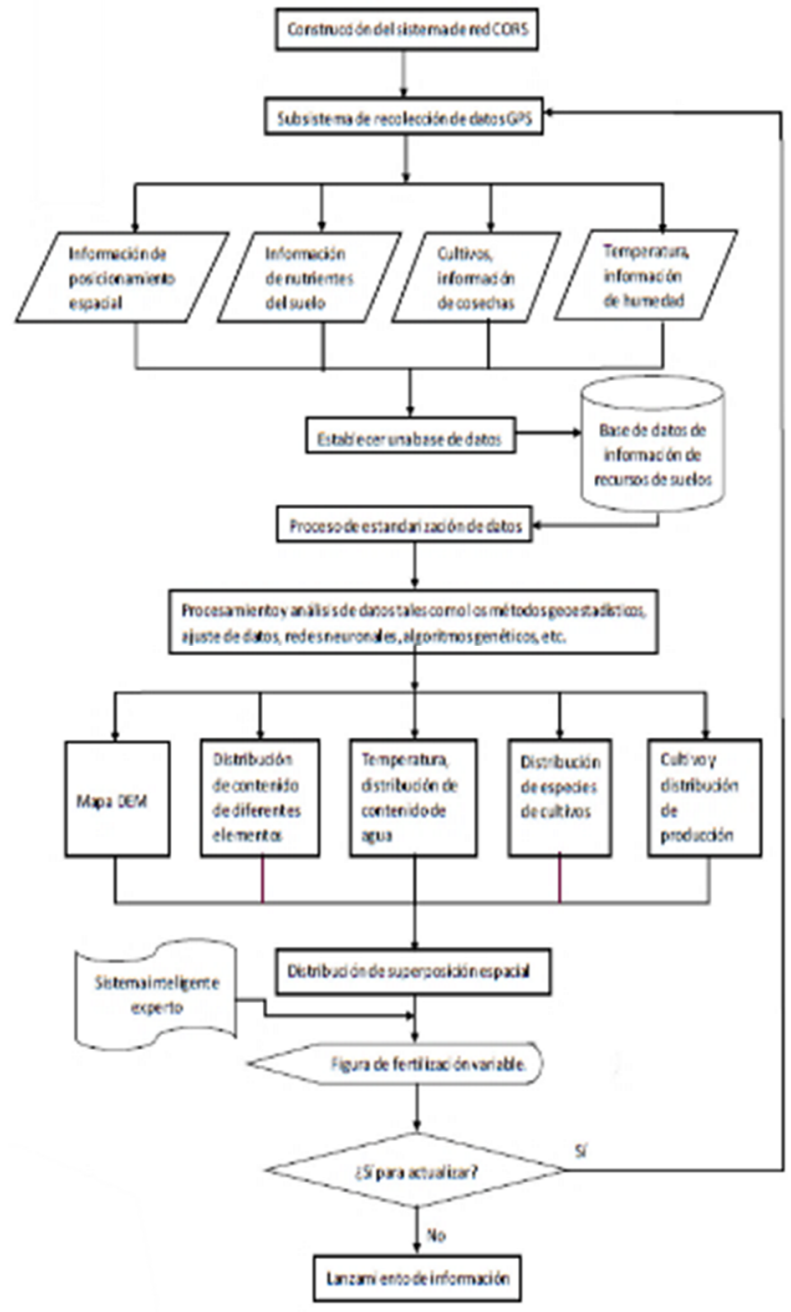

Figura 2. Flujo del proceso en el sistema de manejo de información sobre fertilizantes de precisión

\section{Antecedentes}

Muchos sistemas tecnológicos se han implementado a través de la agricultura de precisión para el mejoramiento de cultivos a nivel mundial. Alguno de los proyectos se basaron en la creación robots que sean capaces de mejorar la 
producción del arroz en exteriores [6], lo que buscamos es elevar el medio de agricultura de precisión en nuestro país.

Nos concentramos en optimizar el proceso de la producción del arroz mediante la eliminación de sus plagas, este proceso de mejoramiento dentro de cultivos ha presentado grandes resultados ya que mediante la agricultura de precisión se pueden colectar una serie de información sumamente útil para el mejoramiento de los cultivos, mediante una data tecnológica [7]. En el campo de la agricultura sostenible, es necesaria la implementación de innovaciones tecnológicas como robots autónomos móviles en agricultura, capaces de desenvolverse en el campo coleccionando data de cultivos y brindando las necesidades de estos, este estudio está en proceso experimental [8].

La visión artificial aplicada a las plantas se presenta en una revisión con implicaciones para el despliegue de campo en operaciones agrícolas automatizadas, siempre se requiere el estudio de los suelos para confirmar el uso viable de este sistema dentro de los cultivos [9].

Previamente al desarrollo de drones en cuanto a aplicaciones como posicionamiento o descarga de fertilizantes dentro de la agricultura de precisión, se tenía la investigación sobre el sistema de control del aplicador de fertilizante de tasa variable en la agricultura de precisión (figura 3) basada en la combinación posicionamiento de GPS, brújula electrónica y giroscopio [10].

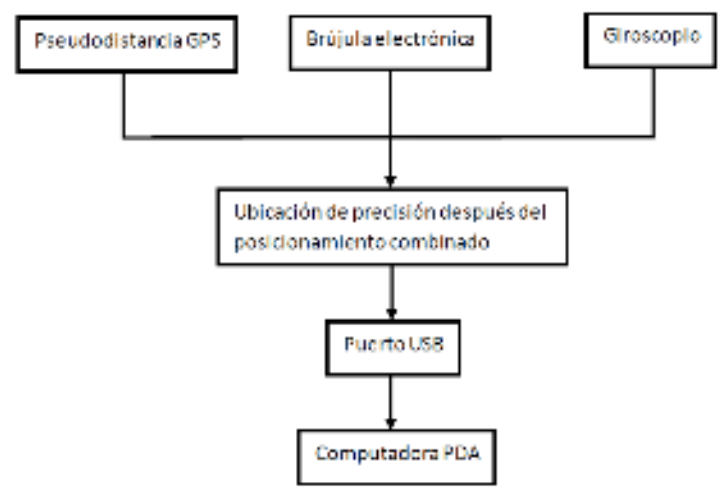

Figura 3. Diagrama del sistema de posicionamiento en la agricultura de precisión, antes de los drones.

En la búsqueda de sensores dentro del área agrícola, los documentos nos proporcionan información como la red de sensores inalámbricos que pueden actuar como un sistema de muestreo distribuido dentro de las aplicaciones agrícolas de precisión que buscan estimar la variabilidad espaciotemporal. Los nodos del sensor se deben utilizar conociendo el rango de comunicación y el rango de muestreo en vez del de detección. [11].

Los sistemas de visión que son empleados para la medición de plantas en los campos agrícolas se necesitan con frecuencia para analizar patrones espaciales, dicho de otra manera, discriminar diferencias y por lo que se necesita que trabajen con alta resolución.

Los objetivos de estos análisis abarcan la predicción y el monitoreo del rendimiento, y la evaluación de las pruebas de manejo en los cultivos [12].

La densidad bacteriana en la bacteria burkholderia glumae presenta gran aumento bajo condiciones ambientales favorables, por tanto, bajo un sistema de regulación denominado quorum sensing, se determinan los procesos de virulencia mediante la activación de genes causantes de la síntesis de la toxoflavina, la cual restringe el flujo de nutrientes, para la biogénesis de flagelos. Las plantas desarrollan la sintomatología que finalmente conlleva a un vaneamiento del grano provocando pérdidas económicas importantes [13].

\section{Método}

La propuesta es utilizar un sistema con el cual se pueda observar los diversos espectros de colores en los cultivos, determinar durante su proceso de crecimiento si tiene o no afectaciones que perjudiquen su desempeño. El sistema se basa en detección de colores mediante una cámara especial de seguimiento.

El equipo que se utilizara está basado en una combinación de Arduino (figura 4) con un sensor de color (Pixy CMU Cam5), el cual tiene la función de reconocer colores, a su vez darles seguimiento a objetos y un drone encargado de movilizar el sensor a través del cultivo. Para la fabricación de nuestro equipo utilizamos los siguientes materiales:

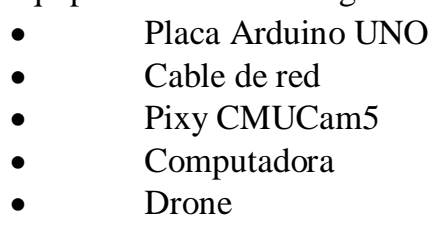

El software necesario se resume en:
- Programa Arduino
- $\quad$ Driver para la placa Arduino

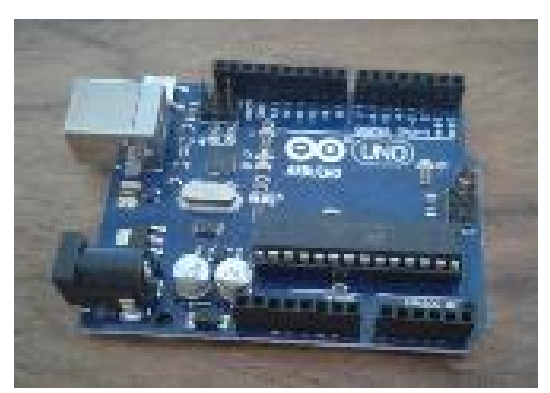

Figura 4. Tarjeta Arduino. 


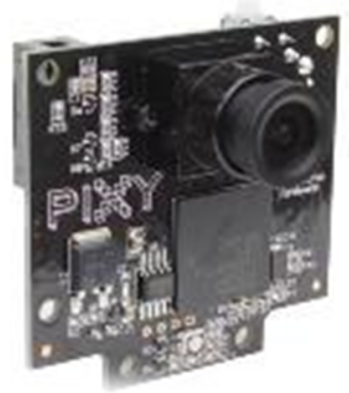

Figura 5. Sensor cámara PIXY CMUCAM5.

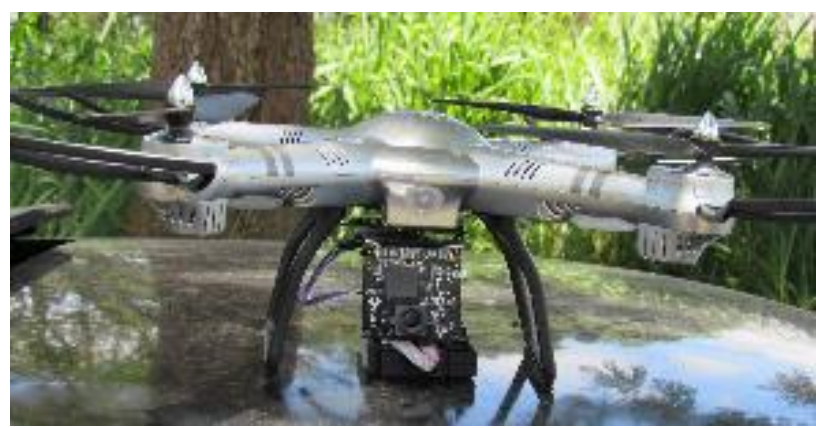

Figura 6. Drone implementado con el sensor PIXY CMUCAM5.

La cámara pixycam5, se utiliza como sensor de color, esta tiene una propiedad de que puede detectar algo fijo, y decirnos en la pantalla cuantas veces el color se repite en la imagen en tiempo real (figura 5). Esta función nos ayuda al poder detectar el color de alguna enfermedad, bacteria, o daño que tenga el cultivo en general.

El Arduino solo es el software para poder verificar los datos obtenidos por la Pixy CMUCam5, que al ser programada da los lugares que se encuentran infectados, detectando la diferencia según el color con que fue programada.

Con la programación, da un color verde a los cultivos sanos, dependiendo el caso. Se hace una gama de colores verdes se toma como referencia y se dice que son cultivos sanos libres de enfermedades.

Cuando se encuentra algún color diferente a la gama de colores verdes, cualquier otro color, lo detecta enseguida y lo marca en la pantalla, dando el posicionamiento de lugar la enfermedad o daño en el cultivo. Para su pronta ayuda, o aplicación del químico.

La propuesta que da este sistema es el observar que lugares están afectados, y poder encontrar esos puntos en los cuales determinara el nivel de enfermedad que tiene el cultivo, con el fin de buscarle una solución lo más pronto posible.

Para empezar, se desarrolla un programa base en programación Arduino (figuras 14 y 15), el cual se enfoca en realizar una distinción de colores y a su vez guardar una data de reconocimiento.
Una vez en campo con el sensor cámara PIXY, graba una planta visiblemente afectada, luego mediante la programación se guarda ese patrón de color para que el sensor lo reconozca como una afectación, después se realiza el mismo procedimiento, pero esta vez con una planta completamente sana.

Ahora bien, ya con la cámara reconociendo los distintos patrones de colores recopilados, se procede con la implementación de esta al drone.

Se realizaron pruebas de vuelo para determinar el máximo rango de altura entre el cultivo y el sensor para que se identifiquen los colores adecuadamente, mediante las mediciones se marcó como una altura promedio indicada de dos metros entre la planta y la cámara.

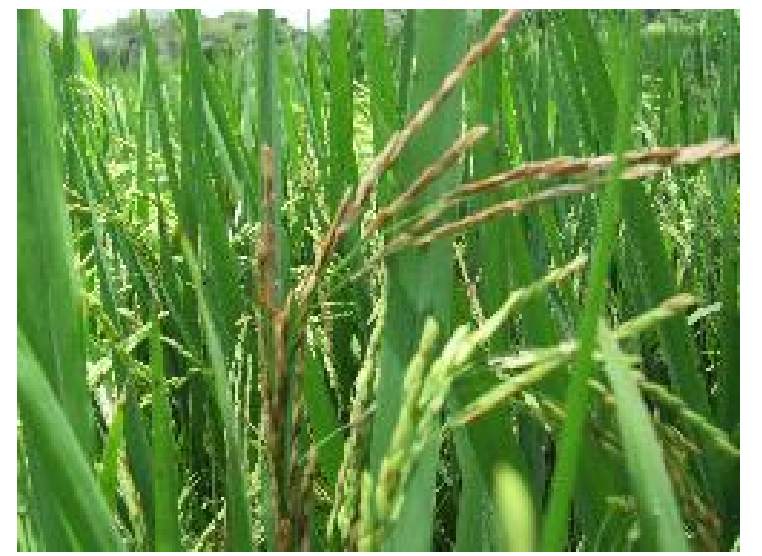

Figura 7. Fotografía tomada en campo dentro del cultivo en presencia de una afectación por bacteria.

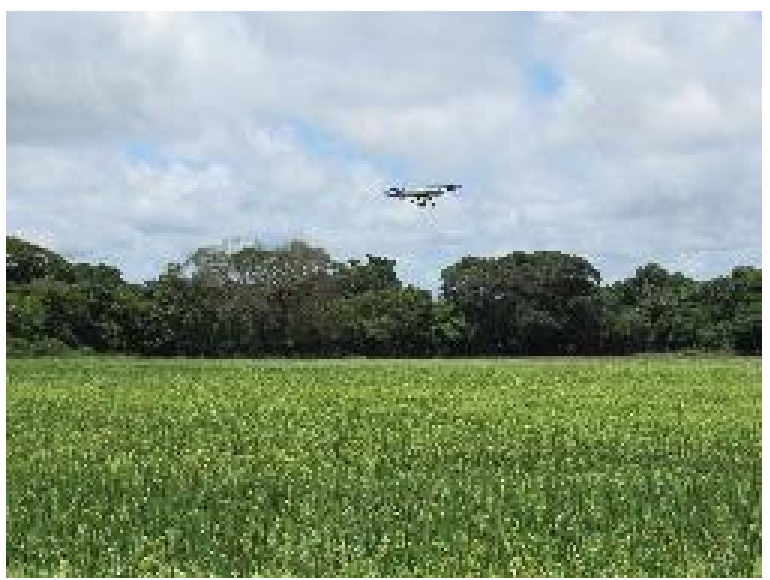

Figura 8. Drone con el sensor realizando las pruebas de campo para la detección de patrones de color.

\section{Resultados}

En primer lugar, se detecta una afectación en las hojas del cultivo, la misma se reconoce con el sensor y se marca su patrón específico dentro de la base de datos.

La coloración presentada es un amarillo-rojizo debido a una deficiencia de fosforo dentro del cultivo. 


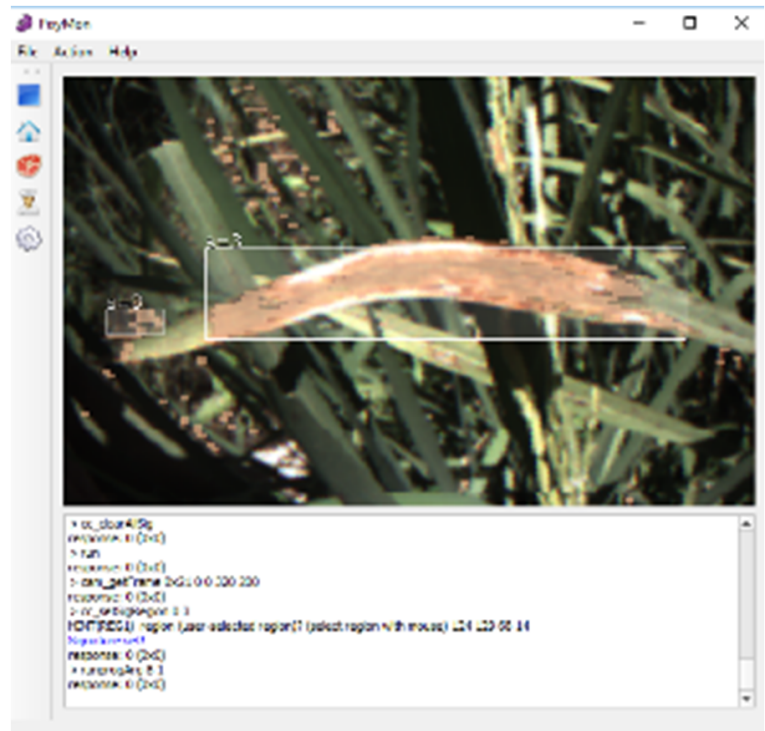

Figura 9. S=3 Afectación en la misma hoja de la planta un color rojizo amarillo.

Otro punto es la presencia de vaneamiento en las plantas de arroz debido a la bacteria burkholderia glumae, la cual deja un color amarillento en la misma, dentro del campo se graba el patrón de color provocado por la bacteria y se sube a la base de datos, una vez dentro, la cámara al pasar por el cultivo reconoce las áreas afectadas.

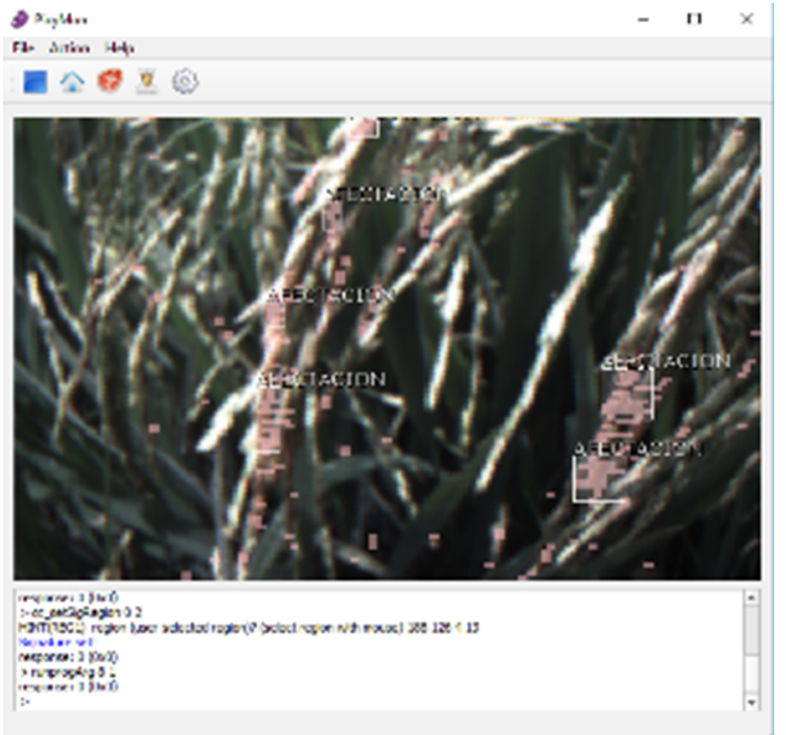

Figura 10. Afectaciones en la planta de arroz debido a la bacteria burkholderia glumae.

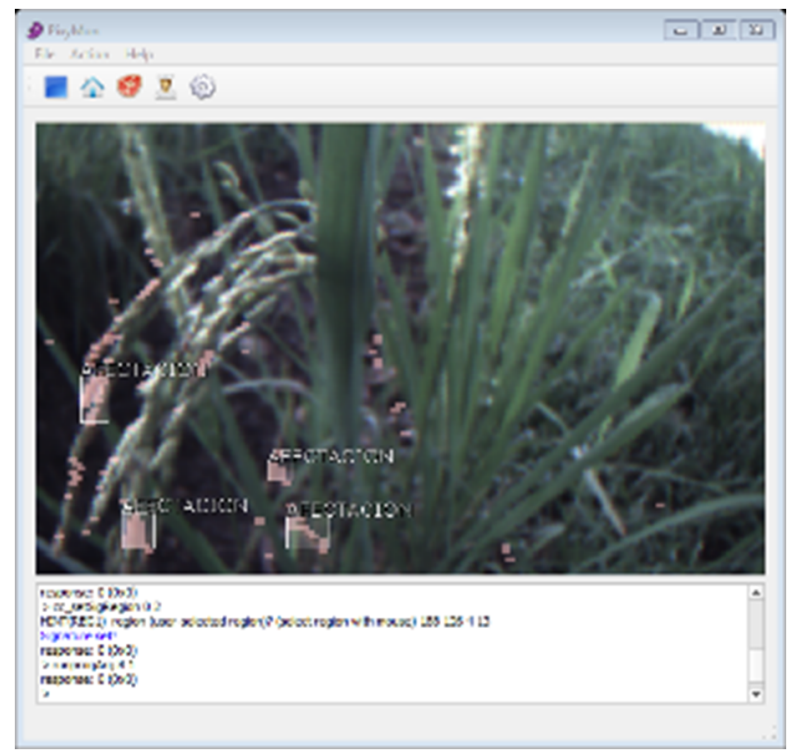

Figura 11. Afectaciones del vaneamiento mostrada por nuestro sensor.

Ahora bien, también se realizaron pruebas y toma de data en un cultivo completamente sano, para de igual manera grabar su patrón de color, con lo cual se puede realizar la comparación entre un cultivo afectado y uno sano.

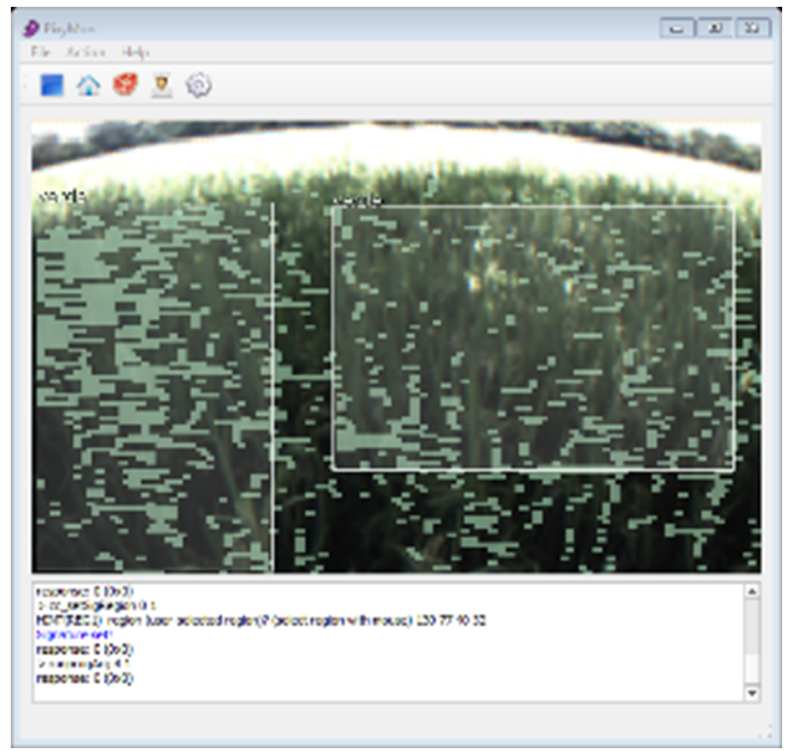

Figura 12. Patrón de color en un cultivo sano.

El cultivo cuenta con un total de 2 hectáreas el equivalente a 20000 metros cuadrados, la zona afectada representa un 5\% el equivalente a una zona de 1000 metros cuadrados.

Se determina que la zona afectada por la bacteria representa un porcentaje bajo dentro de la producción del cultivo, con lo cual se puede tratar de manera rápida y eficiente.

Esta información se logra obtener mediante marcaciones realizadas en el campo, donde el drone marca afectación se coloca un indicador como una bandera, a medida que se 
mueve se obtiene un inicio y fin de zona, estas se van midiendo, así es como se determinó el área afectada.

Sin embargo, este tipo de bacteria se debe tratar lo mas pronto posible de lo contrario puede llegar a presentar grandes pérdidas económicas dentro de la producción.

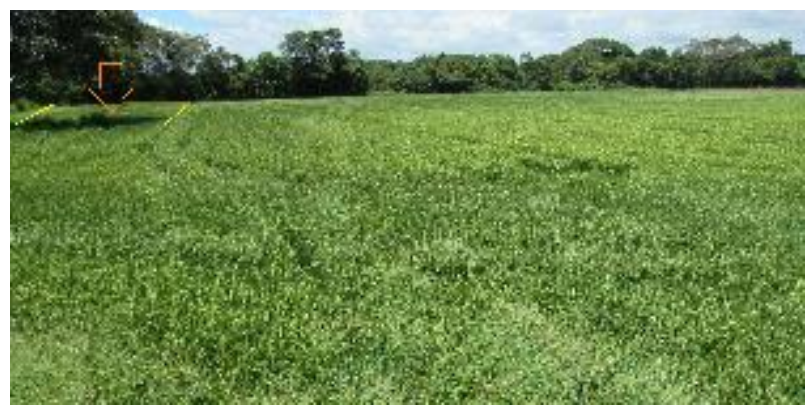

Figura 13. Parte de la zona afectada dentro del cultivo (señalizada con la flecha).

La PIXY CMUCAM5 cuenta con una aplicación llamada Serial Monitor, con la cual se programan mensajes de alerta que envían la misma al celular mediante bluetooth.

Estos mensajes fueron programados para indicar tres tipos de situaciones distintas:

1. La planta se encuentra sana: este mensaje se da cuando el sensor detecta solamente el patrón preestablecido como sano.

2. La planta se encuentra enferma: este mensaje se da cuando el sensor detecta una mezcla del patrón de colores de afectación y el sano.

3. La planta esta muerta: este mensaje se da cuando el sensor detecta solamente el patrón preestablecido como afectación.
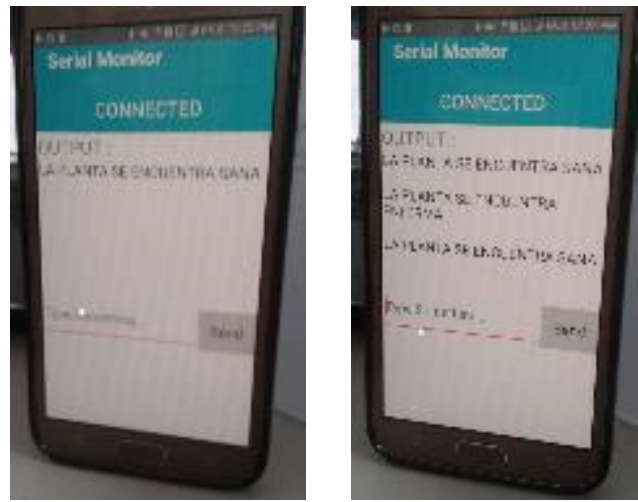

Figura 14. dos tipos de alertas programadas, detectadas y enviadas al celular (sana y enferma).

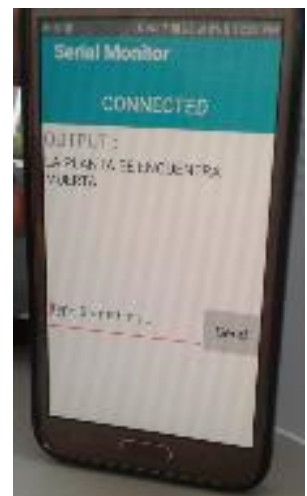

Figura 15. Tercer tipo de alerta enviada al celular (afectación total en la planta).

La programación del sensor se realizó mediante Arduino, con el cual se hizo la rutina de reconocimiento para los distintos patrones de colores y a su vez el mensaje alerta enviados al móvil.

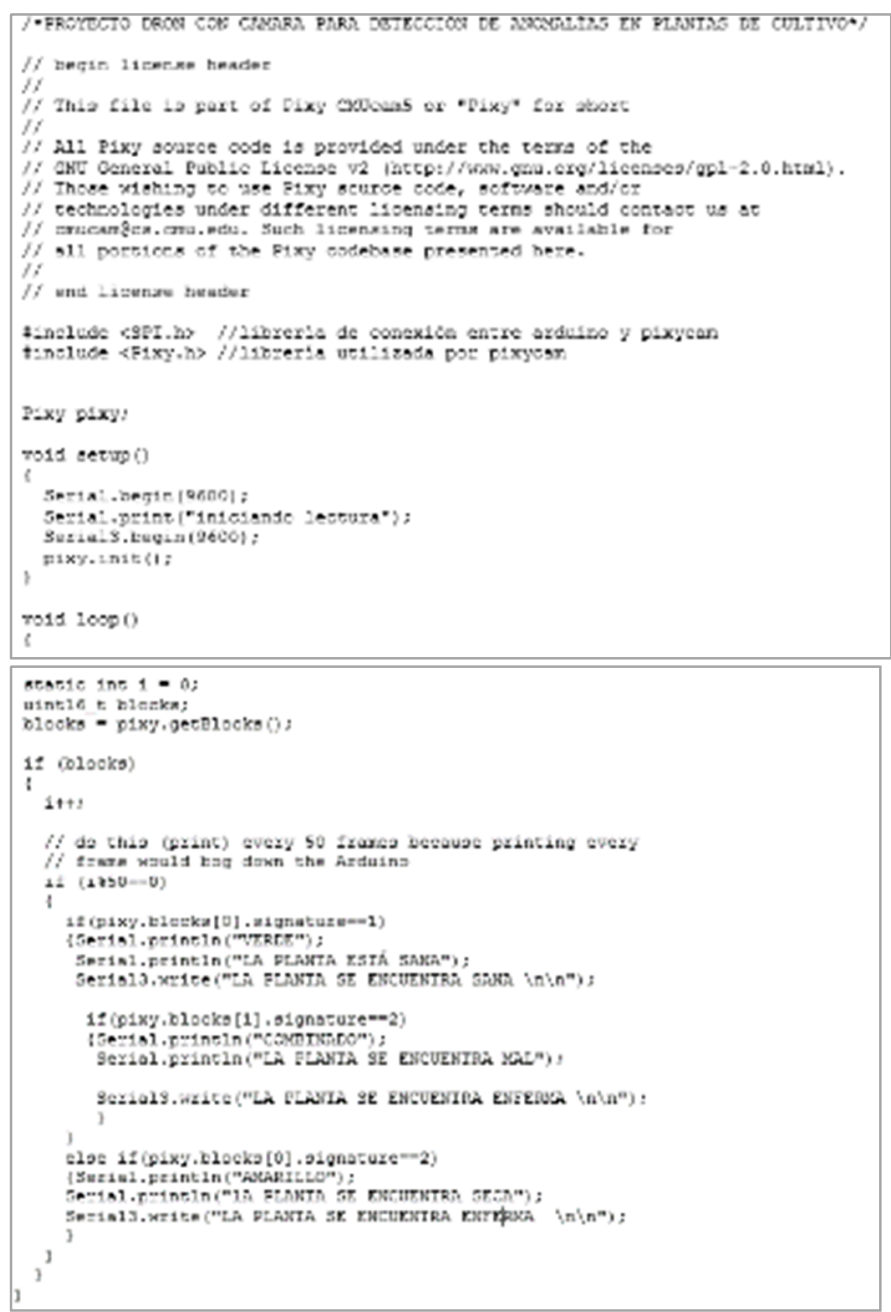

Figura 16. Código en Arduino para muestras de alertas en afectaciones presentadas por el cultivo. 


\section{Conclusiones}

Los resultados obtenidos al realizar las pruebas de recopilación de información en trata de enfermedades del cultivo arroz, pueden ser extrapolados a cualquier otro monocultivo que exista, puesto que todos al padecer alguna enfermedad muestran un cambio de color.

Además de la utilización de la Pixy CMUCam5 se puede utilizar una tarjeta llamada 1sheeld, con la cual, se puede observar el patrón de colores a través de la cámara la cual se instala hasta cualquier dispositivo móvil.

Con la realización del proyecto, se resuelven problemas en control de gastos para los agricultores, se corrige las afectaciones por eutrofización y se mejora la calidad alimenticia de los productos.

El arroz es uno de los principales alimentos de nuestro país, y se ve diezmado en ocasiones por las distintas plagas que no son tratadas de forma correcta o simplemente no se localizaron a tiempo, se puede corregir esto de manera sustancial, al implementar la caza de enfermedades con drones.

Actualmente en Panamá solo se llevó a cabo este experimento en forma controlada por el IDIAP para el control de malezas en una tomatera, el cual presento buena perspectiva.

Panamá no cuenta con una base de datos dentro de la detección de cambios en color de plantas para la trata de enfermedades, sin embargo, en otros países como China o, Estados Unidos, si se ha realizado y se tiene muy buenos resultados de estos, por lo que se busca implementarlo en nuestras tierras.

La bacteria encontrada fue burkholderia glumae la cual es relativamente nueva en nuestras zonas, esta causa un vaneamiento en la planta del arroz el cual son granos vacíos, esto representa pérdidas económicas fuertes en la producción de no tratarse adecuadamente y en el tiempo de su esparcimiento.

\section{AGRADECIMIENTO}

Ante todo, dar gracias a Dios, por permitir desarrollar esta idea y brindar sabiduría, salud y paciencia.

Se agradece a Ganadería La Yeguada, S.A. por permitir realizar la investigación dentro de los terrenos de su finca ubicada en David, Chiriquí.

\section{REFERENCIAS}

[1] C. Quality and F. Insect, "The Effects of Low - Dose Gamma Ir radiation and Storage Time on Carotenoids, Antioxidant Activity, and Phenolic in the Potato Cultivar Atlantic," no. September 2006, pp. 125-131, 2007.

[2] L.H. R. L. Winston and M. Schwarzla, "Biological control of weeds : an analysis of introductions, rates of establishment and estimates of success, worldwide," pp. 319-331, 2018.

[3] I. C. Buitrago; E.I.Q. MacIntire; and B. Z. Salamina, Innovación tecnológica para el manejo integrado del cultivo de arroz en panamá.

[4] IDIAP, "Memoria Memoria memoria," 2018.

[5] Z. Liu, W. Xiong, and X. Cao, "Design of Precision Fertilization Management Information System on GPS and GIS Technologies * The Development of Precision Fertilization Based on GPS," pp. 268-277.

[6] A. Baerveldt, "An Agricultural Mobile Robot with Vision-Based Perception for Mechanical Weed Control,” pp. 21-35, 2002.

[7] G. Burlacu, R. Costa, J. Sarraipa, and R. Jardim-goncalves, "A Conceptual Model of Farm Management Information System for Decision Support," pp. 47-54, 2014.

[8] H. Hagras, M. Colley, V. Callaghan, and M. Carr-west, "Online Learning and Adaptation of Autonomous Mobile Robots for Sustainable Agriculture," pp. 37-52, 2002.

[9] Y. He, "Effects of land use intensity on soil nutrient distribution after reclamation in an estuary landscape," pp. 699-707, 2013.

[10] G. Pan and X. Feng, "Research on Control System of Variable Rate Fertilizer Applicator in Precision Farming Based on Combined Positioning of GPS , Electronic Compass and Gyroscope * Outline of Precision Farming and the Main Technological,” pp. 188-192.

[11] H. Liu, Z. Meng, H. Wang, and M. Xu, "Systematic Random Deployment for Wireless Sensor Network in Agricultural Sampling-Interpolation,” pp. 53-59.

[12] C.L.M.N.H.H.S.R. Raine, "Applied machine vision of plants : a review with implications for field deployment in automated farming operations," pp. 209-217, 2010.

[13] Andrea Quesada-González2 Burkholderia glumae en el cultivo de arroz en costa rica, Agron. Mesoam. 25(2):371-381. 2014 